\title{
Physical Activity, Sedentary Behavior, and Diet-Related eHealth and mHealth Research: Bibliometric Analysis
}

Andre Matthias Müller ${ }^{1,2}, \mathrm{PhD}$; Carol A Maher ${ }^{3}, \mathrm{PhD}$; Corneel Vandelanotte ${ }^{4}, \mathrm{PhD}$; Melanie Hingle ${ }^{5}, \mathrm{PhD}$; Anouk Middelweerd $^{6}$, PhD; Michael L Lopez ${ }^{7}$, MUP; Ann DeSmet ${ }^{8,9}$, PhD; Camille E Short ${ }^{10}$, PhD; Nicole Nathan ${ }^{11,12,13}$, $\mathrm{PhD}$; Melinda J Hutchesson ${ }^{14}$, PhD; Louise Poppe ${ }^{8,9}$, MSc; Catherine B Woods ${ }^{15}$, PhD; Susan L Williams ${ }^{4}, \mathrm{PhD}$; Petra A Wark ${ }^{16}, \mathrm{PhD}$

${ }_{1}^{1}$ Domain: Health Systems \& Behavioural Sciences, Saw Swee Hock School of Public Healh, National University of Singapore, Singapore, Singapore

${ }^{2}$ Sports Centre, University of Malaya, Kuala Lumpur, Malaysia

${ }^{3}$ School of Health Sciences, University of South Australia, Adelaide, Australia

${ }^{4}$ Physical Activity Research Group, School of Health, Medical and Applied Sciences, Central Queensland University, Rockhampton, Australia

${ }^{5}$ Department of Nutritional Sciences, College of Agriculture and Life Sciences, The University of Arizona, Tucson, AZ, United States

${ }^{6}$ EMGO Institute for Health and Care Research, Department of Epidemiology and Biostatistics, VU University Medical Centre, Amsterdam, Netherlands

${ }^{7}$ Texas A\&M AgriLife Extension Service, Texas A\&M University, College Station, TX, United States

${ }^{8}$ Department of Movement and Sports Sciences, Faculty of Medicine and Health Sciences, Ghent University, Ghent, Belgium

${ }^{9}$ Research Foundation Flanders, Brussels, Belgium

${ }^{10}$ Freemasons Foundation Centre for Men's Health, Faculty of Health Sciences, University of Adelaide, Adelaide, Australia

${ }^{11}$ Priority Research Centre for Health Behaviour, School of Medicine and Public Health, The University of Newcastle Australia, Newcastle, Australia

${ }^{12}$ Hunter New England Population Health, Hunter New England Area Health Service, Newcastle, Australia

${ }^{13}$ Hunter Medical Research Institute, Newcastle, Australia

${ }^{14}$ Priority Research Centre in Physical Activity and Nutrition, School of Health Sciences, The University of Newcastle Australia, Newcastle, Australia

${ }^{15}$ Department of Physical Education and Sports Sciences, Faculty of Education and Health Sciences, University of Limerick, Limerick, Ireland

${ }^{16}$ Centre for Innovative Research Across the Life Course, Faculty of Health and Life Sciences, Coventry University, Coventry, United Kingdom

\section{Corresponding Author:}

Andre Matthias Müller, PhD

Domain: Health Systems \& Behavioural Sciences

Saw Swee Hock School of Public Healh

National University of Singapore

Tahir Foundation Building

12 Science Drive, \#10-01

Singapore, 117549

Singapore

Phone: 6582997548

Fax: 6567791489

Email: ephamm@nus.edu.sg

\section{Abstract}

Background: Electronic health (eHealth) and mobile health (mHealth) approaches to address low physical activity levels, sedentary behavior, and unhealthy diets have received significant research attention. However, attempts to systematically map the entirety of the research field are lacking. This gap can be filled with a bibliometric study, where publication-specific data such as citations, journals, authors, and keywords are used to provide a systematic overview of a specific field. Such analyses will help researchers better position their work.

Objective: The objective of this review was to use bibliometric data to provide an overview of the eHealth and mHealth research field related to physical activity, sedentary behavior, and diet.

Methods: The Web of Science (WoS) Core Collection was searched to retrieve all existing and highly cited (as defined by WoS) physical activity, sedentary behavior, and diet related eHealth and mHealth research papers published in English between January 1, 2000 and December 31, 2016. Retrieved titles were screened for eligibility, using the abstract and full-text where 
needed. We described publication trends over time, which included journals, authors, and countries of eligible papers, as well as their keywords and subject categories. Citations of eligible papers were compared with those expected based on published data. Additionally, we described highly-cited papers of the field (ie, top ranked 1\%).

Results: The search identified 4805 hits, of which 1712 (including 42 highly-cited papers) were included in the analyses. Publication output increased on an average of $26 \%$ per year since 2000, with $49.00 \%$ (839/1712) of papers being published between 2014 and 2016. Overall and throughout the years, eHealth and mHealth papers related to physical activity, sedentary behavior, and diet received more citations than expected compared with papers in the same WoS subject categories. The Journal of Medical Internet Research published most papers in the field (9.58\%, 164/1712). Most papers originated from high-income countries $(96.90 \%, 1659 / 1717)$, in particular the United States (48.83\%, 836/1712). Most papers were trials and studied physical activity. Beginning in 2013, research on Generation 2 technologies (eg, smartphones, wearables) sharply increased, while research on Generation 1 (eg, text messages) technologies increased at a reduced pace. Reviews accounted for 20 of the 42 highly-cited papers ( $n=19$ systematic reviews). Social media, smartphone apps, and wearable activity trackers used to encourage physical activity, less sedentary behavior, and/or healthy eating were the focus of 14 highly-cited papers.

Conclusions: This study highlighted the rapid growth of the eHealth and mHealth physical activity, sedentary behavior, and diet research field, emphasized the sizeable contribution of research from high-income countries, and pointed to the increased research interest in Generation 2 technologies. It is expected that the field will grow and diversify further and that reviews and research on most recent technologies will continue to strongly impact the field.

(J Med Internet Res 2018;20(4):e122) doi: 10.2196/jmir.8954

\section{KEYWORDS}

science; telemedicine; exercise; health behavior; health resources; food; publications; movement; trends; Internet

\section{Introduction}

Being regularly active, having a less sedentary lifestyle, and consuming a healthy diet has many benefits for physical health, mental health, and well-being [1-3]. This is widely known, and the World Health Organization, the United Nations as well as many governments are committed to promoting these health behaviors [4]. Despite this, many people are not sufficiently active, are too sedentary, and/or do not adhere to dietary recommendations [5-7]. The negative consequences of the high prevalence of unhealthy behaviors are enormous for the individual, health care systems, and economies $[1,6,8]$.

New technologies have been put forward as a cost-effective means to deliver behavioral health interventions and, as a result, prevent noncommunicable diseases (NCD) [9-12]. This is conceivable considering that the availability and personal use of information and communication technologies has increased significantly over the last two decades. Currently, 95\% of the world population is covered by a mobile-cellular network and $84 \%$ is covered by a mobile-broadband network [13]. Although the Internet is still only accessible to $47 \%$ of the world population, access to the World Wide Web and smartphone usage across the globe is continuing to increase rapidly $[13,14]$. As such, there has been a rise in electronic health (eHealth) and mobile health (mHealth) related research for physical activity, sedentary behavior, and diet [10].

Thus far, eHealth and mHealth research related to physical activity, sedentary behavior, and diet has been summarized in several studies that focused on use and effectiveness of different technologies such as mobile phone and/or SMS (short message service) text messaging [15-18], digital games [19,20], the Internet [21-23], smartphone and/or tablet applications [24-28], social media [29], gamification features [30], and fitness trackers $[31,32]$. Other reviews in the field focused on specific

populations such as children and adolescents [33,34], adults [35], older adults [36], overweight and obese adults [37,38], cancer survivors [39], patients with cardiovascular disease [40], and people residing in upper-middle, lower-middle, or low-income countries [41]. In addition, an international workshop addressed how eHealth and mHealth interventions should incorporate psychological theory and behavior change techniques in their design [42].

Although these studies summarized important aspects of the eHealth and mHealth research field related to physical activity, sedentary behavior, and diet, no attempt has been made to map out the entire field in a systematic manner. A bibliometric study uses publication-related information such as citations, journals, authors, and keywords to gain a bird's eye view of a field [43]. Bibliometric studies that summarized the research landscape in various fields have generated valuable insights [43-47] revealing the stage of maturity and growth of a research area, who and where the researchers are that drive the field, which journals are most prominent, and what kind of research is being conducted. This is especially useful in a relatively new research area such as eHealth and mHealth.

The purpose of this study is to examine the eHealth and mHealth research field related to physical activity, sedentary behavior and diet from its infancy until the end of 2016, and provide an overview of highly-cited papers which have considerably contributed to the maturation of the field. This will help researchers better position their work.

\section{Methods}

\section{Search Strategy}

We opted for using the Web of Science (WoS) Core Collection (Clarivate Analytics, USA) because it provides many bibliometric indicators and includes literature from most disciplines. We developed a search strategy in an iterative 
manner starting from search terms used in published reviews and literature already known to us. We refined the search strategy by screening the titles of the most accessed papers listed at websites of journals that publish in the research field, and the titles of all publications of 6 researchers from different countries that are highly active in the field (see Multimedia Appendix 1).

The final search was conducted on April 26, 2017 to ensure all relevant papers that were published between January 1, 2000 and December 31, 2016 were registered in the WoS Core Collection. We used 146 search terms related to (1) physical activity, sedentary behavior, and diet and (2) use of technology (eg, smartphone, Web). Terms were combined with Boolean Operators ("OR" within the two search domains, "AND" between the two search domains). We restricted the search to publications in English and did not search for book chapters, conference proceedings, book citation indexes, and chemical indices (see Multimedia Appendix 2 for the full search strategy).

A second search using the same terms was conducted in which we only retrieved papers that WoS marked as "highly cited." WoS defines "highly cited" as being ranked within the top $1 \%$ compared with all other papers in terms of citation count in the same year and research field [48], suggesting highly-cited papers exert strong impact on the field.

The results of the two searches were exported to Microsoft Excel 2016 for screening.

\section{Screening of Search Results}

We included all journal papers on eHealth and mHealth research related to physical activity, sedentary behavior, and/or diet (including proxies, eg, weight management). They comprisedeHealth and mHealth intervention studies; papers on the components or characteristics of eHealth and mHealth (eg, use of theory in apps); papers on the relationship between technology use and the health behaviors, validation studies of consumer-based assessment tools (eg, Fitbit); and papers on the development of eHealth and mHealth interventions targeting physical activity, sedentary behavior, and/or diet. Reviews, protocols, editorials, commentaries, and original research papers were eligible to gain a comprehensive picture of the field. We excluded papers that were not related to the field (eg, biology papers); reported that technology was only used for data collection (eg, Web-based surveys) or the delivery of education without trying to change behavior (eg, nutrition science course); or were related to validation of research-grade assessment technologies (eg, ActiGraph accelerometers). The detailed screening guide is presented in Multimedia Appendix 3.

We had earlier piloted the screening procedure. Coauthors screened the same set of 20 papers (selected at random from preliminary searches) using a protocol that described the inclusion and exclusion criteria and a tutorial video. The video introduced the overall concept of a bibliometric study compared with a systematic review and detailed the inclusion and exclusion criteria with examples to illustrate how they should be applied [49]. Coauthors indicated whether they would include or exclude a paper or were unsure, while consulting the video, abstract, and full-text upon demand.
Seven trained coauthors (AMM, CAM, CV, MH, MLL, ADS, and PAW) each received a unique set of papers for title screening with optional screening of the abstract and full-text. As in the pilot phase, they chose "include," "exclude," or the option "unsure." Papers marked as unsure were screened by four of the authors (AMM, CAM, CV, and PAW) and discussed until consensus was reached.

\section{Bibliometric Analysis}

We computed the (compound) growth rate of publications over time. This was done by raising the ratio of the number of publications in 2016 over those in 2000 to the power of 1/16, after which we subtracted one and multiplied by 100 :

growth rate $=\left(\left(\frac{\mathrm{N} \text { publications in } 2016}{\mathrm{~N} \text { publications in } 2000}\right)^{1 / 16}-1\right) * 100$

We calculated the citation rate by dividing the number of citations per publication by the time since publication until December 2016, and expressed this per year. The citation rate does not depend on time since publication and is therefore a more precise measure of a paper's research impact than raw citation counts [50,51]. Because citation counts and citation rates are usually not normally distributed $[47,52]$, we reported medians and interquartile ranges when studying their distributions.

Citation trends for physical activity, sedentary behavior, and diet related eHealth and mHealth research were studied between 2007 and 2016 because our analyses made use of published citation rates [53] that are only available over the most recent 10 years. We normalized the citation data for eligible papers by considering the WoS subject category and year in which a paper was published in two ways. First, we assessed the number of papers that occurred within each combination of WoS subject category and publication year among the papers included in our analysis. For each combination of WoS subject category and publication year separately, we multiplied the number of papers by the citation rate derived from the InCites Essential Science Indicator database on June 14, 2017 [53] to obtain the expected number of citations. After summing across WoS subject category, we obtained the total number of expected versus observed citations per year. Second, we compared the number of citations in each year and WoS subject category to corresponding published citation thresholds [53]. This yielded annual percentile scores that indicate the fraction of physical activity, sedentary behavior, and diet related eHealth and mHealth research articles within the top 10\%, 20\%, and 50\% of all articles from the WoS subject categories represented by eligible papers in our search.

We explored the journals and authors who published most papers on eHealth and mHealth related to physical activity, sedentary behavior, and diet, along with the publication output of countries. We used WoS subject categories to count subject fields of papers. For the author analysis, we calculated 2 metrics using data within our dataset only: The $h$-index is the number of eligible papers of an author that were cited at least $h$ times each (eg, an author with an $h$-index of 17 has at least 17 papers that were cited at least 17 times each) [54]. The $g$-index is the unique largest number of top cited eligible papers of an author 
that together received at least $g^{2}$ citations (eg, the 17 top cited articles of an author with a $g$-index of 17 have at least 289 citations jointly) [55]. Countries were classified based on income as defined by the World Bank in 2017 [56].

To analyze the content of our dataset in more detail, we classified eligible papers into categories representing the studied exposure, technology, study population, setting, and methodology used. We did so by searching the title words and keywords identified by the author or by WoS editorial staff for occurrences of relevant terms. We defined the classification search terms using the agreed literature search strategy and the identified keywords in the eligible papers as starting point. The titles and keywords of the papers classified into each category were then double-checked by hand, as were those of all papers that were not classified into any or only a single category. This resulted in a refinement of the classification terms. This process was repeated until no inconsistencies were found. Using the final categorization reported in Multimedia Appendix 4, papers related to the Internet, (mobile) phone, SMS text messages, telehealth, and personal digital assistants were then classified as Generation 1, whereas papers on apps, wearable trackers, exergames, and social media were classified as Generation 2. Papers including both technologies were classified into Generation 2.

For the highly-cited papers, we also analyzed the papers based on their core content. These analyses were conducted independently by 2 coauthors (AMM and AM). They agreed on the descriptions of the paper's core content by also using NVivo 11 (QRS International Pty Ltd, Doncaster, Australia).
We conducted descriptive analyses using Microsoft Excel version 2016 and the Bibliometrix package version 1.7 [57] for $\mathrm{R}$ version 3.3.3 (Vienna, Austria) [58]. We used Stata/SE version 14.2 (College Station, TX, USA) for keyword analysis.

\section{Results}

\section{Results of the Search}

Figure 1 displays the flow of the search and screening procedure. The search resulted in 4805 hits. Of these, 336 were duplicates or conference contributions. Their exclusion led to 4469 papers to be screened. A total of 1712 papers were included in the final bibliometric analysis (Multimedia Appendix 5), 42 of which were highly cited.

\section{Overall Trend}

The number of papers on eHealth and mHealth related to physical activity, sedentary behavior, and diet increased steeply over the 17-year period (mean increase: $26 \%$ per annum). The period between 2014 and 2016 accounted for $49.00 \%$ (839/1712) of all papers (Figure 2).

The 1712 papers received 31,505 citations (median 7 per paper; interquartile range 18.5). Of the 1712 papers, 266 were not cited (15.54\%), while $715(41.67 \%)$ received 1 to 9 citations, 692 received 10 to 99 citations $(40.42 \%)$, and 39 received 100 or more citations $(2.28 \%)$. Overall, each paper received a median number of 2.0 citations per year (interquartile range 4.0).

Figure 1. Screening flowchart.

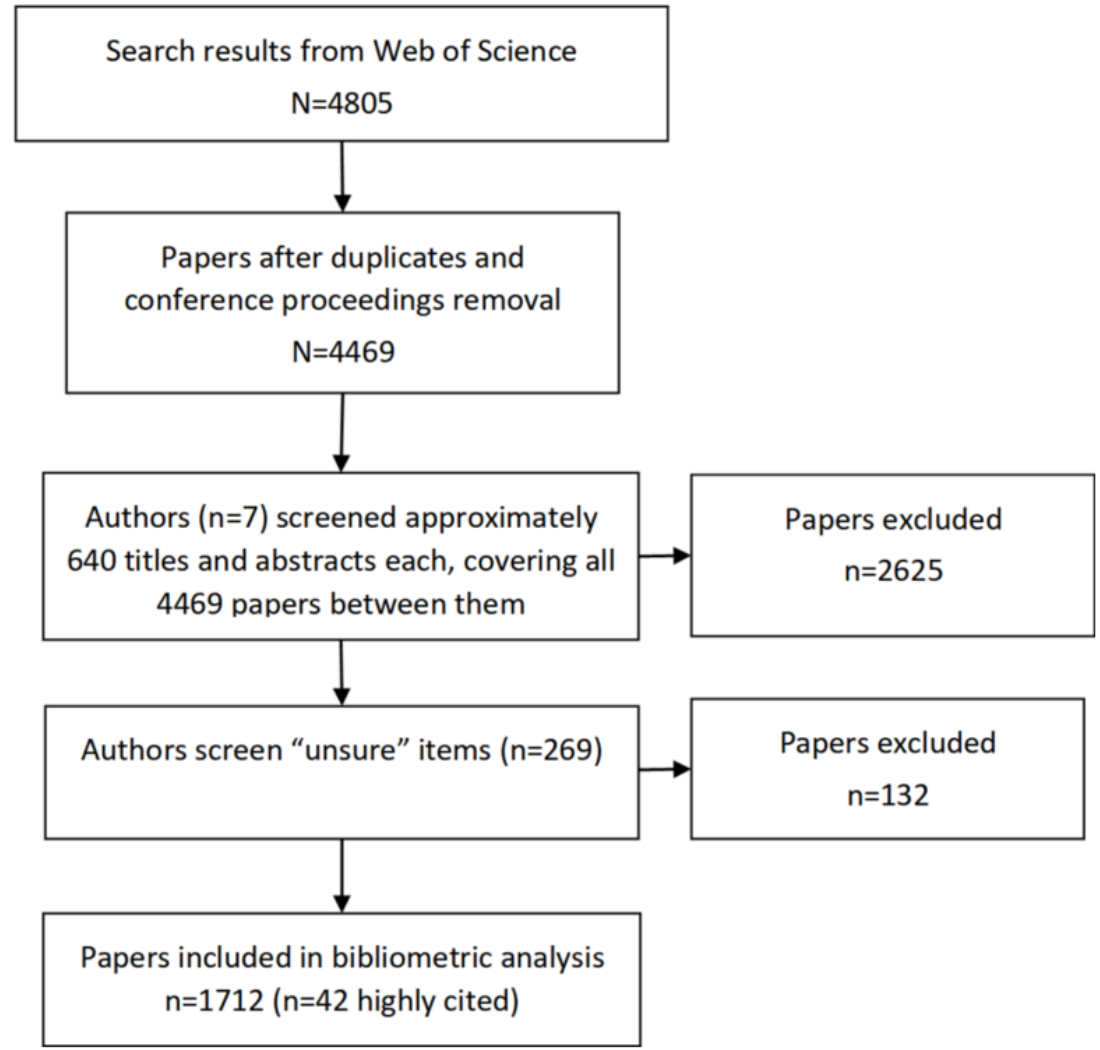


Figure 2. Publication output over time.

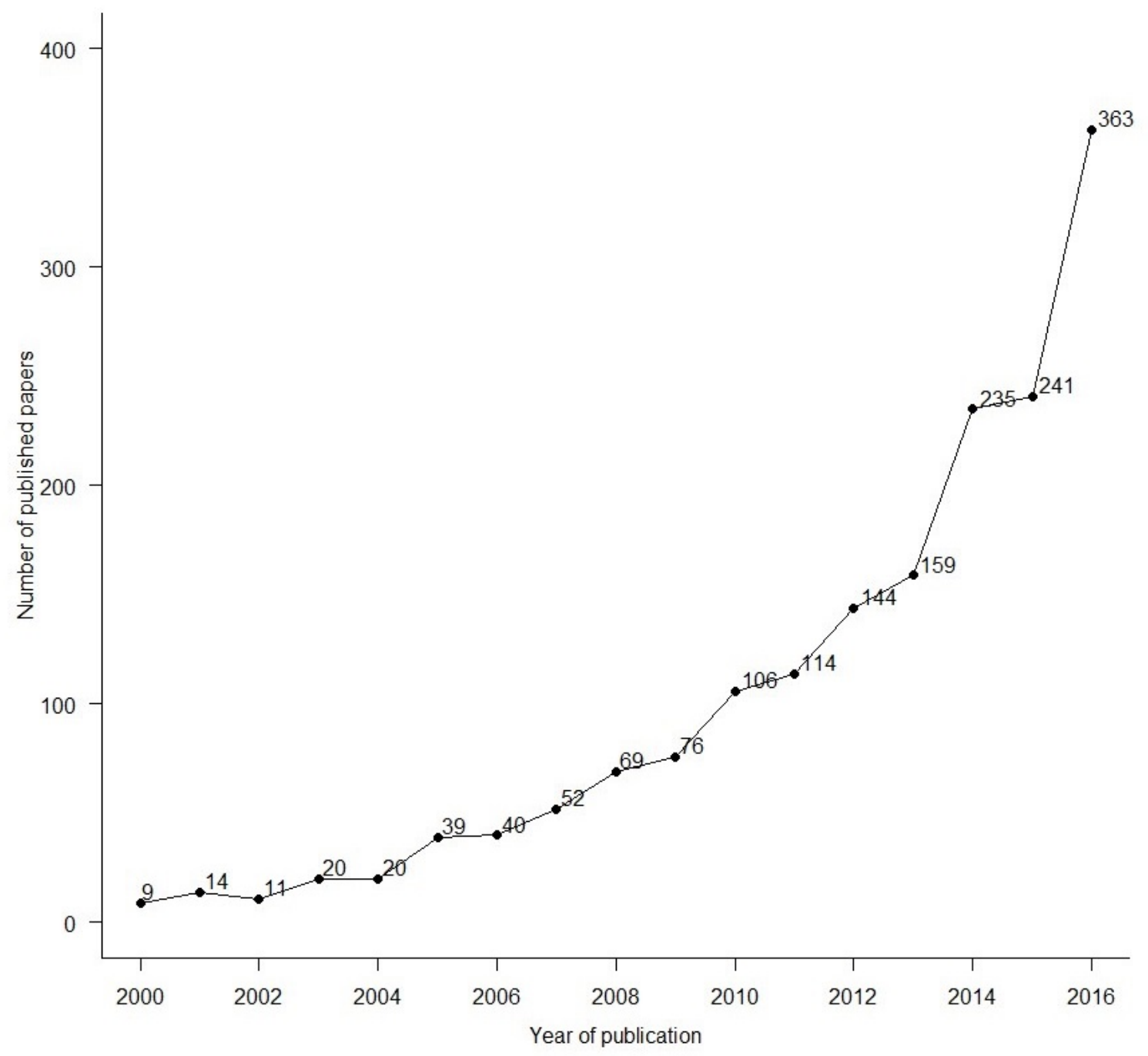

Compared with all papers from the same WoS subject categories, the absolute number of citations was higher than expected for included papers (see Multimedia Appendix 6 for the WoS subject categories of included papers) in all studied years (ie, between 2007 and 2016; results not shown). However, the ratio of the expected to observed citations declined from 2.6 (95\% CI: 2.5-2.7) in 2007 to 1.8 (95\% CI: 1.6-2.0) in 2016. Half of the eHealth and mHealth papers related to physical activity, sedentary behavior, and diet remained in the top 50\% cited papers across same WoS subject categories. However, the proportion of papers in the top $20 \%$ declined from 0.6 to 0.3 between 2007 and 2016 (Figure 3).

\section{Journals and Their Subject Categories}

Overall, the papers were published by 471 different journals. As Table 1 shows, the Journal of Medical Internet Research published the most papers $(9.58 \%, 164 / 1712$ papers $)$ followed by BMC Public Health $(4.15 \%, 71 / 1712)$ and the Games for Health Journal (3.27\%, 56/1712). The Journal of Medical Internet Research was also the highest cited journal and accounted for $13.48 \%$ of all citations in the field $(n=4247$ citations of 31,505 over the 17-year period). The American Journal of Preventive Medicine $(9.37 \%, 2951 / 31,505)$ and
Annals of Behavioral Medicine (4.64\%, 1461/31,505) received the second and third highest number of citations, respectively.

In WoS, papers can be assigned to multiple subject categories. The papers included in this study were assigned to a total of 2797 WoS subject categories, of which 104 subject categories were unique. Table 2 shows the breakdown of subject categories present in the dataset, with only the top 10 categories shown. Throughout the years, the number of papers in journals from most fields gradually increased. However, the number of papers published in rehabilitation, health care science \& services, health policy \& services, as well as in medical informatics journals, increased more markedly from 2012. The number of papers published in psychology journals doubled between 2015 and 2016 (see Multimedia Appendix 6).

\section{Authors}

In total, 5654 authors contributed to the 1712 papers (median number of authors per paper 5 , interquartile range 4$)$. The top 10 authors (Table 3 ) contributed to 298 papers $(17.41 \%$ of all papers). Vandelanotte $C$ contributed to most papers $(n=43)$ followed by Brug J ( $n=34)$, De Bourdeaudhuij I $(n=31)$, and Oenema A $(n=31)$. Vandelanotte $C$ and Marcus B were in the top 10 of all characteristics listed in Table 3, and Brug $\mathrm{J}$ in all but first authorship papers. 
Figure 3. Distribution of physical activity, sedentary behavior, and diet related electronic health (ehealth) and mobile health (mHealth) research papers that were in the top $10 \%, 20 \%, 50 \%$, and $100 \%$ cited among all papers from the same Web of Science (WoS) subject categories by year of publication.

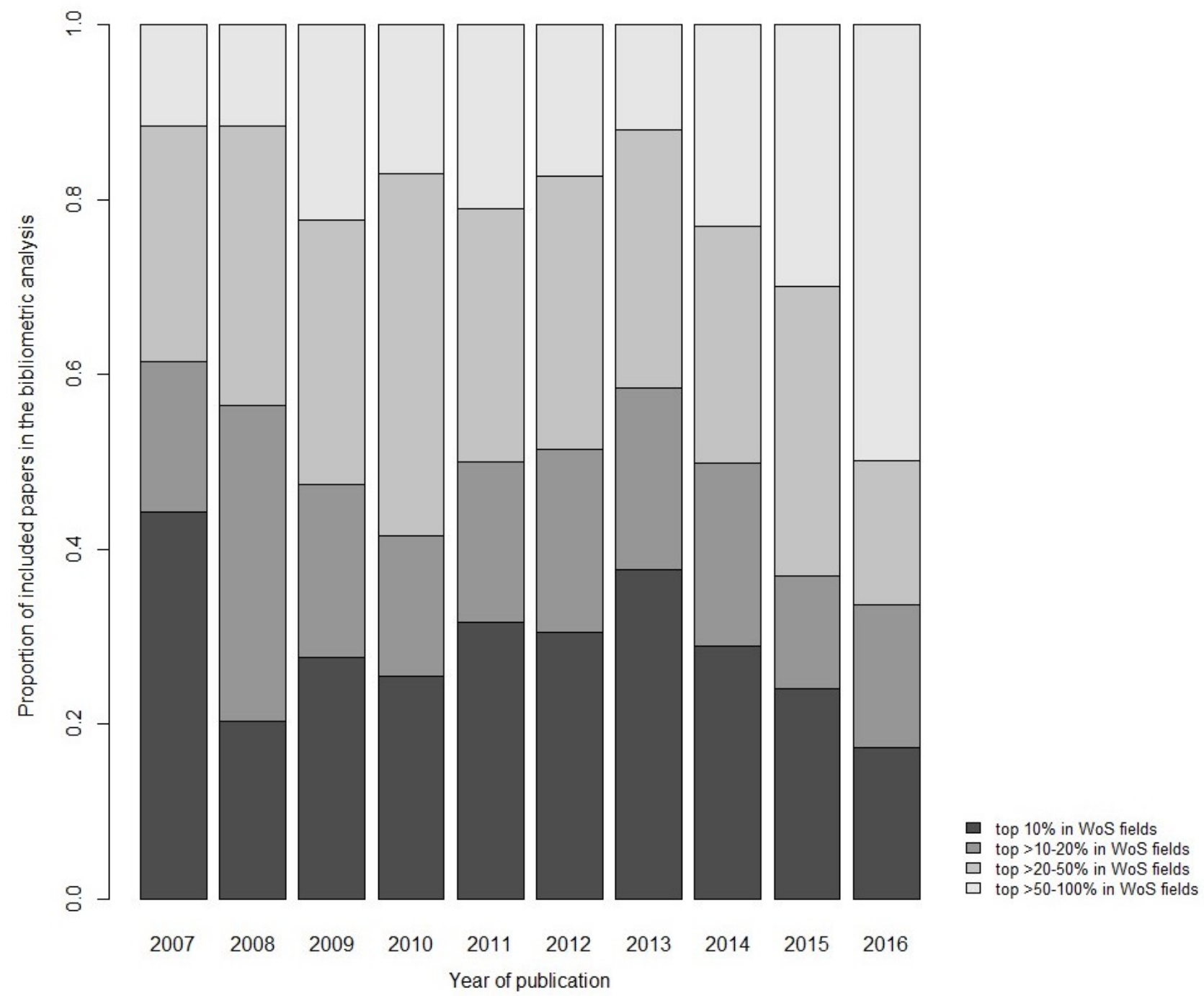

\section{Countries}

As the country of the corresponding author usually indicates where the research originated, we could also analyze the origin of the research that was published in the field. Corresponding authors were from 46 countries (see Multimedia Appendix 7). Most papers were published by authors from the United States ( $\mathrm{n}=836,48.83 \%$ of all published papers) followed by authors from Australia ( $\mathrm{n}=195,11.39 \%)$ and the Netherlands $(\mathrm{n}=125$, $7.30 \%)$. Overall, $96.90 \%(n=1659)$ of all papers published were authored by researchers from high-income countries. Of the remaining 53 papers, 45 were published by authors from 9 upper-middle income countries: China $(n=21)$, Malaysia $(n=7)$, Iran $(n=4)$, Brazil $(n=3)$, Turkey $(n=3)$, Thailand $(n=2)$, Lebanon $(\mathrm{n}=2)$, Romania $(\mathrm{n}=2)$, and Mexico $(\mathrm{n}=1)$. Papers published by authors from lower-middle income countries accounted for only $0.005 \%$ of all papers and came from India ( $n=4)$, Pakistan $(n=1)$, Nigeria $(n=1)$, Egypt $(n=1)$, and the Philippines $(n=1)$. Similar

patterns appeared when considering coauthorship or first authors instead of corresponding authors (data not shown).

\section{Keywords}

Authors specified a total of 2448 different keywords across papers. After also adding the keywords specified by WoS editors, this resulted in 4283 unique keywords. The number of keywords per paper varied widely (median 12, interquartile range 6). A total of 43 papers lacked specification of any keywords. The keywords that were most used reflected the exposure (eg, "physical-activity"), the general topic (ie, "health"), the study design (eg, "randomized controlled-trial"), or the population (eg, "adults"). Several of the keywords, including commonly used ones, were uninformative by themselves (eg, "risk," "program"). We were able to use the keywords in combination with title words to classify the content of the paper into categories. 
Table 1. Journals publishing most papers in physical activity, sedentary behavior, and diet electronic- and mobile health (eHealth and mHealth) research (top 20).

\begin{tabular}{|c|c|c|c|c|c|c|}
\hline Journals & $\begin{array}{l}\text { Rank based on } \\
\text { total output }\end{array}$ & $\begin{array}{l}\text { Papers } \\
\text { published } \\
(\mathrm{N}=1712), \\
\mathrm{n}(\%)\end{array}$ & $\begin{array}{l}\text { Rank based on } \\
\text { total citations } \\
\text { received from } \\
\text { any journal }\end{array}$ & $\begin{array}{l}\text { Citation count } \\
(\mathrm{N}=31,505), \\
\mathrm{n}(\%)\end{array}$ & $\begin{array}{l}\text { Impact } \\
\text { factor } \\
2016^{\mathrm{a}}\end{array}$ & $\begin{array}{l}\text { 5-year } \\
\text { impact } \\
\text { factor }^{\mathrm{a}}\end{array}$ \\
\hline Journal of Medical Internet Research & 1 & $164(9.58)$ & 1 & $4247(13.48)$ & 5.175 & 5.835 \\
\hline BMC Public Health & 2 & $71(4.15)$ & 7 & $640(2.03)$ & 2.265 & 2.814 \\
\hline Games for Health Journal & 3 & $56(3.27)$ & 21 & $307(0.97)$ & 2.019 & 2.242 \\
\hline JMIR mHealth uHealth & 4 & $50(2.92)$ & 26 & $240(0.76)$ & 4.636 & 4.463 \\
\hline American Journal of Preventive Medicine & 5 & $40(2.34)$ & 2 & $2951(9.37)$ & 4.020 & 5.412 \\
\hline $\begin{array}{l}\text { International Journal of Behavioral Nutrition and Physical } \\
\text { Activity }\end{array}$ & 6 & $38(2.22)$ & 8 & $529(1.68)$ & 4.396 & 5.813 \\
\hline Journal of Nutrition Education and Behavior & 6 & $38(2.22)$ & 10 & $597(1.89)$ & 2.491 & 2.439 \\
\hline Preventive Medicine & 8 & $29(1.69)$ & 4 & $1038(3.29)$ & 3.434 & 3.703 \\
\hline Journal of Physical Activity and Health & 9 & $27(1.58)$ & 36 & $176(0.56)$ & 1.946 & 2.400 \\
\hline Obesity & 10 & $25(1.46)$ & 5 & $1032(3.28)$ & 3.873 & 4.358 \\
\hline Health Education Research & 10 & $25(1.46)$ & 6 & $781(2.48)$ & 1.816 & 2.183 \\
\hline PLoS One & 12 & $24(1.40)$ & 28 & $238(0.76)$ & 2.806 & 3.394 \\
\hline Telemedicine Journal and E-Health & 12 & $24(1.40)$ & 37 & $174(0.55)$ & 2.031 & 2.141 \\
\hline Annals of Behavioral Medicine & 14 & $23(1.34)$ & 3 & $1461(4.64)$ & 2.976 & 4.508 \\
\hline Computers in Human Behavior & 14 & $23(1.34)$ & 46 & $121(0.38)$ & 3.435 & 4.252 \\
\hline Journal of Telemedicine and Telecare & 14 & $23(1.34)$ & 17 & $372(1.18)$ & 2.008 & 2.371 \\
\hline JMIR Research Protocols & 14 & $23(1.34)$ & 68 & $79(0.25)$ & N/A & N/A \\
\hline Patient Education Counseling & 18 & $21(1.23)$ & 16 & $374(1.19)$ & 2.429 & 3.042 \\
\hline Translational Behavioral Medicine & 19 & $19(1.11)$ & 33 & $221(0.70)$ & 2.989 & 2.883 \\
\hline American Journal of Health Promotion & 20 & $17(0.99)$ & 18 & $361(1.15)$ & 2.586 & 2.280 \\
\hline
\end{tabular}

${ }^{\mathrm{a}}$ Obtained from InCites Journal Citation Reports (Clarivate Analytics).

Table 2. Number of papers published in journals within the top 10 leading Web of Science (WoS) subject categories. Each paper can be assigned to multiple WoS subject categories (according to the categories specified at journal level).

\begin{tabular}{lll}
\hline WoS subject category & $\begin{array}{l}\text { Different journals within WoS subject } \\
\text { category, } \mathrm{n}\end{array}$ & $\begin{array}{l}\text { Papers in journals within WoS subject } \\
\text { category }(\mathrm{N}=2797), \mathrm{n}(\%)\end{array}$ \\
\hline Public, environmental \& occupational health & 70 & $457(16.34)$ \\
Health care sciences \& services & 32 & $346(12.37)$ \\
Nutrition \& dietetics & 46 & $247(8.83)$ \\
Psychology & 53 & $217(7.76)$ \\
Medical informatics & 19 & $214(7.65)$ \\
Medicine & 30 & $145(5.18)$ \\
Education \& education research & 8 & $103(3.68)$ \\
Endocrinology \& metabolism & 30 & $96(3.43)$ \\
Rehabilitation & 28 & $94(3.36)$ \\
Health policy \& services & 12 & $78(2.79)$ \\
\hline
\end{tabular}


Table 3. Top 10 most published authors in electronic health (eHealth) and mobile health (mHealth) physical activity, sedentary behavior, and diet related research in either number of papers, first authored papers, citations, $h$-or $g$-index.

\begin{tabular}{|c|c|c|c|c|c|}
\hline Author & All papers, n (rank) & First authored papers, $n$ (rank) & Citations, $\mathrm{n}$ (rank) & $h$-index ${ }^{\mathrm{a}}$ (rank) & $g$-index ${ }^{\mathrm{a}}$ (rank) \\
\hline Vandelanotte C & $43(1)$ & $13(1)$ & $1379(3)$ & $17(2.5)$ & $37(1)$ \\
\hline Brug J & $34(2)$ & $2(180)$ & $1666(1)$ & $19(1)$ & $34(2)$ \\
\hline Oenema A & $31(3.5)$ & $3(71)$ & $980(5)$ & $12(9)$ & $31(3)$ \\
\hline De Bourdeaudhuij I & $31(3.5)$ & $2(180)$ & $788(9)$ & $16(4.5)$ & $28(5)$ \\
\hline Marcus B & $29(5.5)$ & $7(4)$ & $1089(4)$ & $16(4.5)$ & $29(4)$ \\
\hline De Vries H & $29(5.5)$ & $1(764.5)$ & $404(31)$ & $11(13)$ & $19(12.5)$ \\
\hline Thompson D & $27(7)$ & $10(2)$ & $696(13)$ & $11(13)$ & $26(6)$ \\
\hline Collins C & $25(8.5)$ & $4(30)$ & $618(17)$ & $11(13)$ & $24(7.5)$ \\
\hline Maddison R & $25(8.5)$ & $5(15)$ & $404(31)$ & $10(18.5)$ & $19(12.5)$ \\
\hline Morgan P & $24(10)$ & $3(71)$ & $669(15)$ & $13(7)$ & $24(7.5)$ \\
\hline Tate D & $23(11)$ & $3(71)$ & $1512(2)$ & $17(2.5)$ & $23(9)$ \\
\hline Eakin E & $21(13.5)$ & $7(4)$ & $869(7)$ & $13(7)$ & $21(10.5)$ \\
\hline Baranowski T & $21(13.5)$ & $6(8)$ & 748 (10) & $11(13)$ & $21(10.5)$ \\
\hline Owen N & $15(22.5)$ & $0(1677.5)$ & $955(6)$ & $13(7)$ & $15(21.5)$ \\
\hline
\end{tabular}

${ }^{\mathrm{a}}$ Within our dataset only.

We classified $888(51.87 \%)$ papers as studying Generation 1 technologies and $742(43.34 \%)$ papers as studying Generation 2 technologies, with $82(4.79 \%)$ papers being still unclassified. Before 2014, studies on Generation 1 technologies were most common. From 2014 onwards, studies on Generation 2 technologies were most common; their number steeply increased between 2013 and 2016. Within this period, the number of studies on Generation 1 technologies increased less markedly (Figure 4). Vandelanotte $\mathrm{C}$ was the most common first author of papers on Generation 1 technologies $(n=11)$, followed by Harvey-Berino $\mathrm{J}(\mathrm{n}=6)$. Gao $\mathrm{Z}$ was the most common first author of papers on Generation 2 technologies $(n=7)$, followed by Baranowski T $(\mathrm{n}=6)$.

Table 4 summaries the frequency of key study characteristics of the included papers. Physical activity was the health behavior most commonly targeted, followed by articles on weight and diet. Most studies targeted children or adolescents, while fewer focused on men and older adults. Multimedia and computer-based technologies (other than mobile apps) were most commonly studied, followed by studies focused on gamification or games, wearable technology or self-monitoring, or mobile apps or smartphones. Most studies were experimental trials, followed by reviews and/or meta-analyses. Few studies made use of creative or mixed methods.

\section{Highly-Cited Papers}

A table with all highly-cited papers can be found in Multimedia Appendix 8.

The 42 highly-cited papers received a total of 4883 citations (median 91, interquartile range 170) and were published between
2006 and 2016 across 19 journals. The American Journal of Preventive Medicine $(\mathrm{n}=13)$ and the Journal of Medical Internet Research ( $\mathrm{n}=6)$ published most highly-cited papers. Corresponding authors were from nine countries, with US-based authors being the most common $(\mathrm{n}=20)$, followed by authors from Australia $(n=8)$ and the United Kingdom $(n=5)$. Overall, 226 authors contributed to the 42 highly-cited papers (mean 5.2 authors per paper) with Vandelanotte $C(n=5)$ and Brug $J(n=4)$ contributing to most highly-cited papers.

A systematic review and meta-analysis that reported on the link between intervention characteristics and intervention effectiveness on health behaviors (including physical activity and diet) in Internet interventions had the highest citation rate (79.5 citations per year) [59]. The authors included 85 studies and found that more extensive use of theory, a higher number of behavior change techniques and additional modes of communication (especially, text messages) were associated with larger effect sizes.

Of the 42 highly-cited papers, 20 were reviews of the literature, of which 19 used a systematic review approach, (4 of which also conducted a meta-analysis). A total of 13 papers reported data from primary studies and most of these were experimental trials such as randomized controlled trials $(n=10) ; 8$ studies reported content analyses of various smartphone apps, and 1 study introduced an eHealth and mHealth intervention development methodology. In terms of the technology used, 14 of the highly-cited papers studied Generation 2 technologies, the majority of which related to social media, apps, or trackers $(n=11)$. Most of the highly-cited papers were published in 2013 or later. 
Figure 4. Number of published papers that studied Generation 1 technologies and Generation 2 technologies.

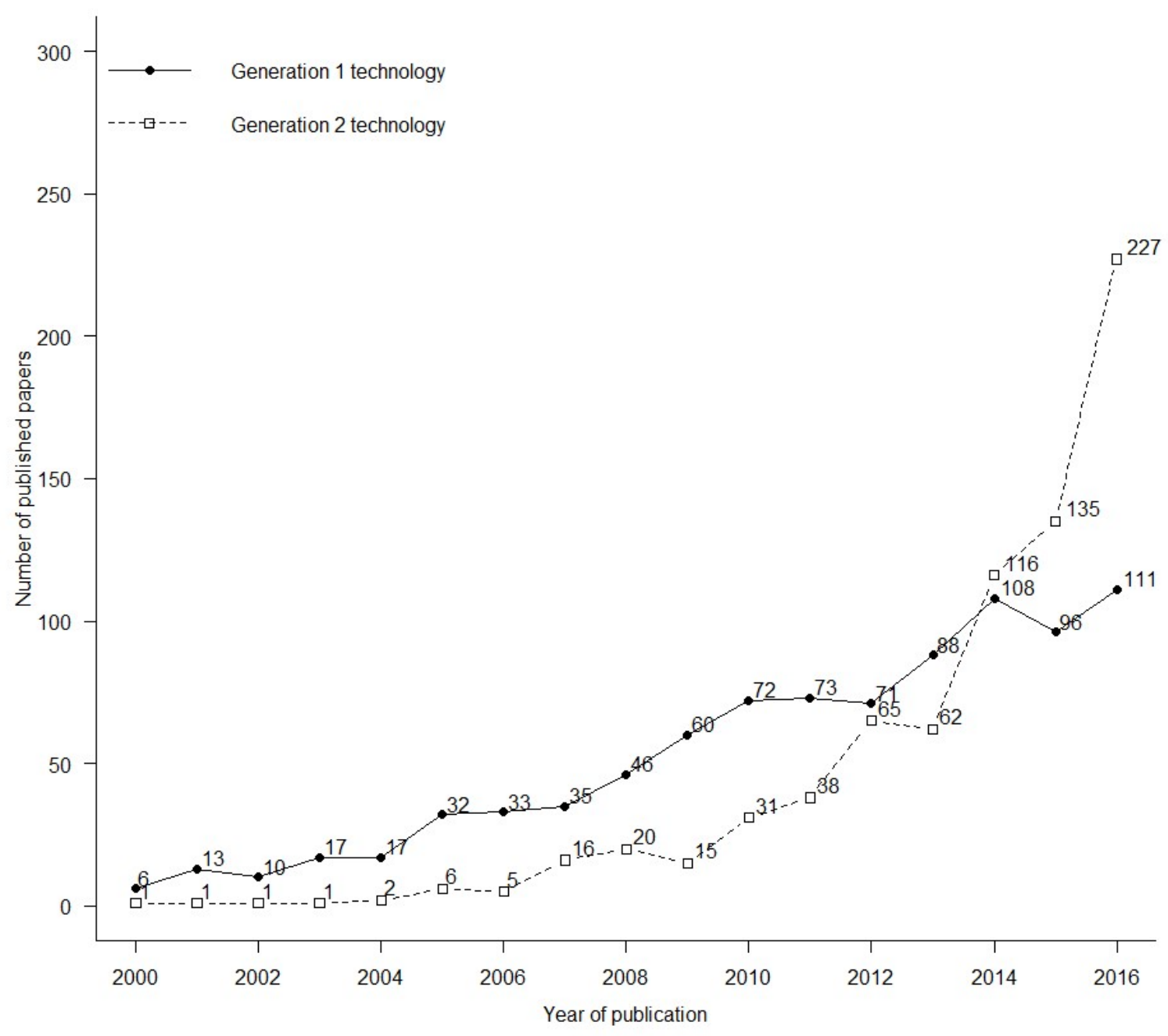


Table 4. Description of the physical activity, sedentary behavior, and diet related electronic health (eHealth) and mobile health (mHealth) research using expressions found in titles keywords of identified papers.

\section{Modifiable factors}

Physical activity

$1236(72.19)$

Weight-related

859 (50.18)

Diet or nutrition

$621(36.27)$

Sedentary behavior

$169(9.87)$

\section{Technology}

Multimedia and computer-based technologies other than mobile apps

$906(52.92)$

Gamification or games

302 (17.64)

Wearable technology or self-monitoring

Mobile apps or smartphones

Telehealth

$191(11.16)$

Text message

177 (10.34)

Social media or marketing

$89(5.20)$

\section{Populations}

Adults

Adolescents or youth

406 (23.71)

Children or infants

400 (23.36)

Older adults

Women

Men

\section{Setting}

School or university

Workplace

Community

Low- or middle-income countries, or low-income settings

Family

\section{Research methodology/focus}

Experimental trial

Review and/or meta-analysis

Qualitative study

Observational study

Costs (including cost-effectiveness and financial incentives)

Creative methods or designs

Mixed methods (including Delphi studies)

$10(0.58)$

${ }^{\text {a }}$ Terms are not mutually exclusive. We used text search to obtain the above categorization, which resulted in a hit if any part of the title or the author-defined and WoS-defined keywords had a specific phrase or word (see methods section and Multimedia Appendix 4). The presented values should thus be used as good indicators rather than absolute values. 


\section{Discussion}

\section{Principal Findings}

The purpose of this paper was to examine the entirety of the eHealth and mHealth research field related to physical activity, sedentary behavior, and diet using bibliometric data. We observed a substantial growth of research output in the field with most papers being published in recent years.

An exponential growth pattern has been observed across all research disciplines. For example, there is a $2.3 \%$ increase in scientific publications per annum leading to a doubling of the publication volume every 24 years [60]. If the overall growth rate we observed also applies to the future, we can expect the publication volume in the physical activity, sedentary behavior, and diet related to eHealth and mHealth research field to double about every 4 years. This strong growth of research output may reflect the fast development, wide availability, and increased functionality and importance of modern technology in people's daily lives. With this, opportunities to use these technologies to address behavioral health arise frequently. Across the world, researchers from various disciplines work on exploiting these new opportunities to understand and ultimately improve behavioral health. New intervention designs, methods, and analysis strategies are being developed [61-64]. We expect that these novel research initiatives will be widely disseminated in the scientific literature, which will likely lead to an increase in the research output. Compared with the entire body of research within the same WoS subject categories, eHealth and mHealth research related to physical activity, sedentary behavior, and diet was more frequently cited than expected. This likely signals an overall interest in the field.

The open access journals Journal of Medical Internet Research and BMC Public Health are the most popular outlets for researchers in this field. The Journal of Medical Internet Research was also the leading journal in an earlier bibliometric study that examined the overall mHealth literature [43]. The leading journals by citation count represent both open-access and nonopen access journals, with the Journal of Medical Internet Research receiving most and the American Journal of Preventive Medicine receiving the second most citations, respectively. Journals that publish open access enjoy a citation advantage in terms of speed of building up citations and overall citation count $[65,66]$. However, the size of this effect seems to be field-specific, which might explain why many nonopen access journals that publish physical activity, sedentary behavior, and diet eHealth and mHealth papers also accumulated a high number of citations $[67,68]$. The ranking of citation counts per journal is only a crude approximation of a journal's impact, as journals that publish more papers enjoy more opportunities to receive citations.

While eHealth and mHealth research related to physical activity, sedentary behavior, and diet is maturing rapidly in many high-income countries, the research output of non-high-income countries is still meager. Only 3\% of all papers were from upper-middle or lower-middle income countries. None of these countries published many papers in the English language journals included in WoS. It is possible that more papers are published in a local language or in journals not included in WoS. Nonetheless, this observation is unsatisfying, considering that (1) fast globalization and urbanization in many upper-middle and lower-middle income countries is related to reduced physical activity and unhealthy diets, which is associated with an unprecedented rise in NCDs seen in many of these countries $[5,69,70]$ and (2) the (mobile) technology infrastructure is improving rapidly, implying that technology could be used effectively in settings with limited health care resources [71]. Although research in high-income countries is important, the largest public health impacts could be generated in upper-middle, lower-middle and low-income countries where about $80 \%$ of the world population lives. There are signs that physical activity and diet research is slowly increasing in some of these countries [72]. This is promising because resulting findings can be used to address these health behaviors at scale $[41,71,73]$. However, barriers related to funding, prioritization, research capacity and infrastructure, and language need to be overcome.

Although research related to relatively older Generation 1 eHealth and mHealth technologies (eg, Internet, SMS text messages) accounted for most papers in the field, its annual growth rate was $20.0 \%$ compared with $40.4 \%$ for research using Generation 2 technologies such as smartphone apps and wearables. This might indicate that the interest in Generation 1 technologies in the research field is slowly declining as researchers and funding agencies prioritize Generation 2 technologies. The trend of using the newest technologies to address health behaviors is expected to continue, but whether these technologies have a meaningful and long-lasting impact on people's physical activity, sedentary behavior, and dietary habits needs to be seen [10]. Although, there are many arguments to be made for exploring very recent technologies, it is important to consider that these are currently often only available to a limited group of people. In addition, technologies may lose their appeal after a short time or are simply replaced by even newer technologies. These realities present barriers to achieving large-scale and sustainable public health impact with a specific technology.

We also found that most papers in the field were on physical activity compared with sedentary behavior and/or diet. That physical activity research is more common than research on dietary behaviors has been seen in the literature before [74,75]. Research on sedentary behavior is only a recent development as it was previously not distinguished from physical inactivity; a clear operationalization was only published recently [76]. Hence, to date, not many researchers have conducted eHealth and mHealth studies targeting sedentary behavior. Currently, only one review on eHealth and mHealth intervention studies targeting sedentary behavior exists [35].

We identified 42 highly-cited papers, which exert a strong influence on the field. These papers may be a resource for those less familiar with the field. The largest proportion of the highly-cited papers employed a systematic review approach to provide an overview of certain subfields. Systematic reviews and meta-analyses attract a high number of citations [77] as they are at the top of the evidence hierarchy in health-related subjects [78]. They are also important for researchers, policy 
makers, and practitioners alike. Intervention studies, such as randomized controlled trials, were also highly cited. However, their influence may decrease when more such studies in a specific area (eg, SMS text messaging interventions) accumulate and systematic reviews become available.

\section{Strengths and Limitations}

The strength of this paper is that it provides a comprehensive overview of the eHealth and mHealth research field related to physical activity, sedentary behavior, and diet. To capture all relevant papers, we consulted the literature, discussed search terms, executed pilot searches, and refined our search before conducting the final search (with almost 150 search terms). We were similarly systematic in our paper-screening procedure. With this, we are confident that we have identified most eHealth and mHealth research papers related to physical activity, sedentary behavior, and diet.

We conducted a keyword analysis in combination with a title search to gain an insight into the studied exposures, technologies, populations, settings, and used methodologies. Because we did not confirm the obtained classification by retrieving the full-text, the number of papers for each category and subcategory we reported remains an estimate. However, this method allowed us to form an impression of the type of eHealth and mHealth research on physical activity, sedentary behavior, and diet that has been conducted between 2000 and 2016. Using keywords that are often used in a field is beneficial because others who consult databases to identify relevant research are likely to use these terms [79]. If authors use common keywords for their papers, database users are more likely to discover their work. This will also increase publication impact. Finally, in addition to providing an overview of the overall research in the field, we identified and analyzed highly-cited papers and highly published authors. This is important considering that, across all fields, only a small number of papers and authors determine the direction of a field $[47,52]$.

Despite these strengths, limitations of our work need to be acknowledged. First, we only obtained papers from journals indexed by a single database-WoS. However, WoS is a large database that offers a wide variety of publication metrics that were vital for our analyses. Additionally, WoS only includes journals that meet certain criteria (eg, timely publishing, innovation, international diversity) to ensure high quality (more than 12,500 journals are currently indexed). Despite likely having excluded eligible papers in journals not included in WoS, we obtained papers from high-quality international journals that are the most influential source of scientific communication [52]. Using other databases such as Scopus could be explored in future studies. Second, we may have missed some papers that do not use informative keywords in the title as we did not search terminology used in abstracts. We did not review reference lists of eligible papers or their citations to identify any potentially missing papers. This, however, limited the (probably large) number of false positive results in our search. Third, we did not include gray literature (ie, conference proceedings, books, or other types of publications that are not journal papers), and we did not include papers published in languages other than English. Because of this, we may have missed relevant conference papers from fields such as human-computer interaction, computing, and engineering. Fourth, citation counts and their ranking should be interpreted with caution. Publication and citation habits vary between and even within fields [52]. The papers obtained for our bibliometric analysis were published in a variety of journals, and these journals are generally grouped under many subject categories (by WoS). Even though we considered the expected number of citations for each paper given its publication year and subject category when comparing citation trends over time, our approach remains an approximation: subject categories specified by WoS are assigned at journal level and may not reflect the field of every paper published in that journal. In addition, the citation counts we derived from WoS include self-citations, which may have influenced some of the rankings.

Finally, we have exclusively evaluated the scientific research literature and have identified trends that mainly concern scientific discovery, which will likely impact new research efforts. Therefore, the broader impact of the research outside of academia (eg, on public health, policy) cannot be deduced. Measuring and proving the societal impact of research is essential but difficult, mainly because this impact becomes usually only apparent in the far future and there are no agreed-upon measures to capture impact [80]. However, developments of measuring and analyzing impact beyond the scientific community are underway. One promising group of metrics that can be used are Altmetrics that measure the public engagement with research $[81,82]$.

\section{Conclusions}

In this paper, we provided a bird's eye view of the research on eHealth and mHealth related to physical activity, sedentary behavior, and diet. Our analysis of 1712 papers published between January 2000 and December 2016 showed that research output is increasing rapidly; a trend that appears likely to continue. The Journal of Medical Internet Research was highlighted as the primary outlet for research in the field. Despite the many promising developments, research in upper-middle, lower-middle, and low-income countries is still scant. More research in such settings is needed to examine the public health impact of eHealth and mHealth interventions on physical activity, sedentary behavior, and diet where needed the most. Systematic reviews and papers that report on recent technologies (mainly smartphone apps) exert a strong impact on the field and their influence will likely remain high in the future.

\section{Acknowledgments}

CV is funded through a National Heart Foundation of Australia Future Leader Fellowship (ID 100427). CES is supported by a National Health and Medical Research Council ECR Fellowship (ID 1090517) awarded by the Australian Government. ADS (FWO16/PDO/060, 12H6717N) and LP (11Z4716N) are supported by a Research Foundation Flanders grant. CM is supported by a National Health and Medical Research Council Career Development Fellowship awarded by the Australian Government. 


\section{Authors' Contributions}

AMM, PAW, CV, and CM conceived the study, participated in its design and coordination, and drafted the manuscript. Data analyses were conducted by AMM and PAW. Articles were screened by AMM, PAW, CV, CM, MH, ADS, and MLL. All authors contributed to the writing of the manuscript, provided input on data analysis, and read and approved the final draft.

\section{Conflicts of Interest}

$\mathrm{CV}$ is listed in the manuscript as the author with the most publications in the field as well as most highly cited publications. His input was mostly conceptual, and he was only one of numerous contributors to the development of the search strategy and inclusion and exclusion criteria. He did not conduct any data analyses. He, therefore, did not willingly influence the results.

\section{Multimedia Appendix 1}

Journals and authors searched to refine our search strategy.

[PDF File (Adobe PDF File), 22KB-Multimedia Appendix 1]

\section{Multimedia Appendix 2}

Search strategy (Web of Science).

[PDF File (Adobe PDF File), 25KB-Multimedia Appendix 2]

\section{Multimedia Appendix 3}

Screening guide with inclusion and exclusion criteria.

[PDF File (Adobe PDF File), 32KB-Multimedia Appendix 3]

\section{Multimedia Appendix 4}

Classification of search terms within titles and keywords identified by the author and WoS editorial staff into categories for content analysis.

[PDF File (Adobe PDF File), 143KB-Multimedia Appendix 4]

\section{Multimedia Appendix 5}

File containing the included papers data from Web of Science.

[XLSX File (Microsoft Excel File), 4MB-Multimedia Appendix 5]

\section{Multimedia Appendix 6}

Number of articles per subject category and publication year included in the bibliometric analysis.

[PDF File (Adobe PDF File), 109KB-Multimedia Appendix 6]

\section{Multimedia Appendix 7}

Publication output of countries.

[PDF File (Adobe PDF File), 33KB-Multimedia Appendix 7]

\section{Multimedia Appendix 8}

Highly-cited papers.

[PDF File (Adobe PDF File), 73KB-Multimedia Appendix 8]

\section{References}

1. Biddle SJ, Bennie JA, Bauman AE, Chau JY, Dunstan D, Owen N, et al. Too much sitting and all-cause mortality: is there a causal link? BMC Public Health 2016 Jul 26;16:635 [FREE Full text] [doi: 10.1186/s12889-016-3307-3] [Medline: 27456959] 
2. Oyebode O, Gordon-Dseagu V, Walker A, Mindell JS. Fruit and vegetable consumption and all-cause, cancer and CVD mortality: analysis of Health Survey for England data. J Epidemiol Community Health 2014 Sep;68(9):856-862 [FREE Full text] [doi: 10.1136/jech-2013-203500] [Medline: 24687909]

3. Blair SN, Morris JN. Healthy hearts--and the universal benefits of being physically active: physical activity and health. Ann Epidemiol 2009 Apr;19(4):253-256. [doi: 10.1016/j.annepidem.2009.01.019] [Medline: 19344864]

4. World Heatlh Organization (WHO). Global status report on noncommunicable diseases 2014 URL: http://apps.who.int/ iris/bitstream/10665/148114/1/9789241564854_eng.pdf?ua=1[WebCite Cache ID 6tW7zibkY]

5. Sallis JF, Bull F, Guthold R, Heath GW, Inoue S, Kelly P, Lancet Physical Activity Series 2 Executive Committee. Progress in physical activity over the Olympic quadrennium. Lancet 2016 Sep 24;388(10051):1325-1336. [doi: 10.1016/S0140-6736(16)30581-5] [Medline: 27475270]

6. Lim SS, Vos T, Flaxman AD, Danaei G, Shibuya K, Adair-Rohani H, et al. A comparative risk assessment of burden of disease and injury attributable to 67 risk factors and risk factor clusters in 21 regions, 1990-2010: a systematic analysis for the Global Burden of Disease Study 2010. Lancet 2012 Dec 15;380(9859):2224-2260 [FREE Full text] [doi: 10.1016/S0140-6736(12)61766-8] [Medline: 23245609]

7. Matthews CE, Chen KY, Freedson PS, Buchowski MS, Beech BM, Pate RR, et al. Amount of time spent in sedentary behaviors in the United States, 2003-2004. Am J Epidemiol 2008 Apr 1;167(7):875-881 [FREE Full text] [doi: 10.1093/aje/kwm390] [Medline: 18303006]

8. Ding D, Lawson KD, Kolbe-Alexander TL, Finkelstein EA, Katzmarzyk PT, van Mechelen W, Lancet Physical Activity Series 2 Executive Committee. The economic burden of physical inactivity: a global analysis of major non-communicable diseases. Lancet 2016 Sep 24;388(10051):1311-1324. [doi: 10.1016/S0140-6736(16)30383-X] [Medline: 27475266]

9. Rehman H, Kamal AK, Sayani S, Morris PB, Merchant AT, Virani SS. Using mobile health (mHealth) technology in the management of diabetes mellitus, physical inactivity, and smoking. Curr Atheroscler Rep 2017 Apr;19(4):16. [doi: 10.1007/s11883-017-0650-5] [Medline: 28243807]

10. Vandelanotte C, Müller AM, Short CE, Hingle M, Nathan N, Williams SL, et al. Past, present, and future of eHealth and mHealth research to improve physical activity and dietary behaviors. J Nutr Educ Behav 2016 Mar;48(3):219-228.e1. [doi: 10.1016/j.jneb.2015.12.006] [Medline: 26965100]

11. Burke LE, Ma J, Azar KMJ, Bennett GG, Peterson ED, Zheng Y, American Heart Association Publications Committee of the Council on Epidemiology and Prevention, Behavior Change Committee of the Council on Cardiometabolic Health, Council on Cardiovascular and Stroke Nursing, Council on Functional Genomics and Translational Biology, Council on Quality of Care and Outcomes Research, Stroke Council. Current science on consumer use of mobile health for cardiovascular disease prevention: a scientific statement from the American Heart Association. Circulation 2015 Sep 22;132(12):1157-1213. [doi: 10.1161/CIR.0000000000000232] [Medline: 26271892]

12. World Health Organization. Geneva: World Health Organization; 2011. mHealth new horizons for health through mobile technologies: Based on the findings of the second global survey on eHealth URL: http://www.who.int/goe/publications/ goe mhealth web.pdf [WebCite Cache ID 6xzuC9000]

13. International Telecommunication Union (ICT). ICT facts and figures 2016 URL: $\underline{\text { http://www.itu.int/en/ITU-D/Statistics/ }}$ Documents/facts/ICTFactsFigures2016.pdf[WebCite Cache ID 6qaDn5Qza]

14. Statistica. Number of smartphone users worldwide from 2014 to 20202017 URL: https://www.statista.com/statistics/330695/ number-of-smartphone-users-worldwide/ [accessed 2017-05-19] [WebCite Cache ID 6qaFNKE7z]

15. Armanasco AA, Miller YD, Fjeldsoe BS, Marshall AL. Preventive health behavior change text message interventions: a meta-analysis. Am J Prev Med 2017 Mar;52(3):391-402. [doi: 10.1016/j.amepre.2016.10.042] [Medline: 28073656]

16. Siopis G, Chey T, Allman-Farinelli M. A systematic review and meta-analysis of interventions for weight management using text messaging. J Hum Nutr Diet 2015 Feb;28 Suppl 2:1-15. [doi: 10.1111/jhn.12207] [Medline: 24480032]

17. Stephens J, Allen J. Mobile phone interventions to increase physical activity and reduce weight: a systematic review. J Cardiovasc Nurs 2013;28(4):320-329 [FREE Full text] [doi: 10.1097/JCN.0b013e318250a3e7] [Medline: 22635061]

18. Buchholz SW, Wilbur J, Ingram D, Fogg L. Physical activity text messaging interventions in adults: a systematic review. Worldviews Evid Based Nurs 2013 Aug;10(3):163-173. [doi: 10.1111/wvn.12002] [Medline: 23746267]

19. DeSmet A, van Ryckeghem D, Compernolle S, Baranowski T, Thompson D, Crombez G, et al. A meta-analysis of serious digital games for healthy lifestyle promotion. Prev Med 2014 Dec;69:95-107. [doi: 10.1016/j.ypmed.2014.08.026] [Medline: 25172024]

20. Peng W, Crouse JC, Lin JH. Using active video games for physical activity promotion: a systematic review of the current state of research. Health Educ Behav 2013 Apr;40(2):171-192. [doi: 10.1177/1090198112444956] [Medline: 22773597]

21. Bardus M, Smith JR, Samaha L, Abraham C. Mobile phone and Web 2.0 technologies for weight management: a systematic scoping review. J Med Internet Res 2015;17(11):e259 [FREE Full text] [doi: 10.2196/jmir.5129] [Medline: 26573984]

22. Davies CA, Spence JC, Vandelanotte C, Caperchione CM, Mummery WK. Meta-analysis of internet-delivered interventions to increase physical activity levels. Int J Behav Nutr Phys Act 2012;9:52 [FREE Full text] [doi: 10.1186/1479-5868-9-52] [Medline: 22546283]

23. Vandelanotte C, Spathonis KM, Eakin EG, Owen N. Website-delivered physical activity interventions a review of the literature. Am J Prev Med 2007 Jul;33(1):54-64. [doi: 10.1016/j.amepre.2007.02.041] [Medline: 17572313] 
24. Schoeppe S, Alley S, Rebar AL, Hayman M, Bray NA, van Lippevelde W, et al. Apps to improve diet, physical activity and sedentary behaviour in children and adolescents: a review of quality, features and behaviour change techniques. Int $\mathrm{J}$ Behav Nutr Phys Act 2017 Jun 24;14(1):83 [FREE Full text] [doi: 10.1186/s12966-017-0538-3] [Medline: 28646889]

25. Schoeppe S, Alley S, van Lippevelde W, Bray NA, Williams SL, Duncan MJ, et al. Efficacy of interventions that use apps to improve diet, physical activity and sedentary behaviour: a systematic review. Int J Behav Nutr Phys Act 2016 Dec 07;13(1):127 [FREE Full text] [doi: 10.1186/s12966-016-0454-y] [Medline: 27927218]

26. Bort-Roig J, Gilson ND, Puig-Ribera A, Contreras RS, Trost SG. Measuring and influencing physical activity with smartphone technology: a systematic review. Sports Med 2014 May;44(5):671-686. [doi: 10.1007/s40279-014-0142-5] [Medline: 24497157]

27. Middelweerd A, Mollee JS, van der Wal CN, Brug J, Te Velde SJ. Apps to promote physical activity among adults: a review and content analysis. Int J Behav Nutr Phys Act 2014;11:97 [FREE Full text] [doi: 10.1186/s12966-014-0097-9] [Medline: 25059981]

28. Flores Mateo G, Granado-Font E, Ferré-Grau C, Montaña-Carreras X. Mobile phone apps to promote weight loss and increase physical activity: A systematic review and meta-analysis. J Med Internet Res 2015;17(11):e253 [FREE Full text] [doi: 10.2196/jmir.4836] [Medline: 26554314]

29. Maher CA, Lewis LK, Ferrar K, Marshall S, De Bourdeaudhuij I, Vandelanotte C. Are health behavior change interventions that use online social networks effective? A systematic review. J Med Internet Res 2014;16(2):e40 [FREE Full text] [doi: 10.2196/jmir.2952] [Medline: 24550083]

30. Looyestyn J, Kernot J, Boshoff K, Ryan J, Edney S, Maher C. Does gamification increase engagement with online programs? A systematic review. PLoS One 2017;12(3):e0173403 [FREE Full text] [doi: 10.1371/journal.pone.0173403] [Medline: 28362821]

31. Direito A, Carraça E, Rawstorn J, Whittaker R, Maddison R. mHealth technologies to influence physical activity and sedentary behaviors: behavior change techniques, systematic review and meta-analysis of randomized controlled trials. Ann Behav Med 2017 Apr;51(2):226-239. [doi: 10.1007/s12160-016-9846-0] [Medline: 27757789]

32. Lewis ZH, Lyons EJ, Jarvis JM, Baillargeon J. Using an electronic activity monitor system as an intervention modality: a systematic review. BMC Public Health 2015;15:585 [FREE Full text] [doi: 10.1186/s12889-015-1947-3] [Medline: 26104189]

33. Turner T, Spruijt-Metz D, Wen CK, Hingle MD. Prevention and treatment of pediatric obesity using mobile and wireless technologies: a systematic review. Pediatr Obes 2015 Dec;10(6):403-409. [doi: 10.1111/ijpo.12002] [Medline: 25641770]

34. Lau PW, Lau EY, Wong DP, Ransdell L. A systematic review of information and communication technology-based interventions for promoting physical activity behavior change in children and adolescents. J Med Internet Res 2011 Jul 13;13(3):e48-e49 [FREE Full text] [doi: 10.2196/jmir.1533] [Medline: 21749967]

35. Stephenson A, McDonough SM, Murphy MH, Nugent CD, Mair JL. Using computer, mobile and wearable technology enhanced interventions to reduce sedentary behaviour: a systematic review and meta-analysis. Int J Behav Nutr Phys Act 2017 Aug 11;14(1):105 [FREE Full text] [doi: 10.1186/s12966-017-0561-4] [Medline: 28800736]

36. Müller AM, Khoo S. Non-face-to-face physical activity interventions in older adults: a systematic review. Int J Behav Nutr Phys Act 2014;11(1):35 [FREE Full text] [doi: 10.1186/1479-5868-11-35] [Medline: 24612748]

37. Hutchesson MJ, Rollo ME, Krukowski R, Ells L, Harvey J, Morgan PJ, et al. eHealth interventions for the prevention and treatment of overweight and obesity in adults: a systematic review with meta-analysis. Obes Rev 2015 May;16(5):376-392. [doi: 10.1111/obr.12268] [Medline: 25753009]

38. Neve M, Morgan PJ, Jones PR, Collins CE. Effectiveness of web-based interventions in achieving weight loss and weight loss maintenance in overweight and obese adults: a systematic review with meta-analysis. Obes Rev 2010 Apr;11(4):306-321. [doi: 10.1111/j.1467-789X.2009.00646.x] [Medline: 19754633]

39. Kopp LM, Gastelum Z, Guerrero CH, Howe CL, Hingorani P, Hingle M. Lifestyle behavior interventions delivered using technology in childhood, adolescent, and young adult cancer survivors: a systematic review. Pediatr Blood Cancer 2017 Jan;64(1):13-17. [doi: 10.1002/pbc.26166] [Medline: 27468131]

40. Duff OM, Walsh DM, Furlong BA, O'Connor NE, Moran KA, Woods CB. Behavior change techniques in physical activity ehealth interventions for people with cardiovascular disease: systematic review. J Med Internet Res 2017 Aug 02;19(8):e281 [FREE Full text] [doi: 10.2196/jmir.7782] [Medline: 28768610]

41. Müller AM, Alley S, Schoeppe S, Vandelanotte C. The effectiveness of e-\& mHealth interventions to promote physical activity and healthy diets in developing countries: a systematic review. Int J Behav Nutr Phys Act 2016 Oct 10;13(1):109 [FREE Full text] [doi: 10.1186/s12966-016-0434-2] [Medline: 27724911]

42. Michie S, Yardley L, West R, Patrick K, Greaves F. Developing and evaluating digital interventions to promote behavior change in health and health care: recommendations resulting from an international workshop. J Med Internet Res 2017 Jun 29;19(6):e232 [FREE Full text] [doi: 10.2196/jmir.7126] [Medline: 28663162]

43. Sweileh WM, Al-Jabi SW, AbuTaha AS, Zyoud SH, Anayah FM, Sawalha AF. Bibliometric analysis of worldwide scientific literature in mobile - health: 2006-2016. BMC Med Inform Decis Mak 2017 May 30;17(1):72 [FREE Full text] [doi: 10.1186/s12911-017-0476-7] [Medline: 28558687] 
44. Andrade A, Dominski FH, Coimbra DR. Scientific production on indoor air quality of environments used for physical exercise and sports practice: bibliometric analysis. J Environ Manage 2017 Jul 01;196:188-200. [doi: 10.1016/j.jenvman.2017.03.001] [Medline: 28284941]

45. Müller AM, Ansari P, Ebrahim NA, Khoo S. Physical activity and aging research: a bibliometric analysis. J Aging Phys Act 2016 Dec;24(3):476-483. [doi: 10.1123/japa.2015-0188] [Medline: 26671908]

46. Şenel E, Demir E. A global productivity and bibliometric analysis of telemedicine and teledermatology publication trends during 1980-2013. Dermatologica Sin 2015 Mar;33(1):16-20. [doi: 10.1016/j.dsi.2014.10.003]

47. van Noorden R, Maher B, Nuzzo R. The top 100 papers. Nature 2014 Oct 30;514(7524):550-553. [doi: 10.1038/514550a] [Medline: 25355343]

48. Web of Science. InCites Essential Science Indicators URL: http://ipscience-help.thomsonreuters.com/incitesLiveESI/ ESIGroup/indicatorsGroup/citationThresholds/thresholdHighlyCited.html[WebCite Cache ID 6sNew7gQp]

49. Müller AM. Youtube.: Study screening guide. Youtube; 2016. e- \& mHealth in physical activity and diet research URL: https://www.youtube.com/watch?v=7p6w0zaTGH8 [accessed 2017-05-21] [WebCite Cache ID 6qce9rsiw]

50. Ho YS. Classic articles on social work field in Social Science Citation Index: a bibliometric analysis. Scientometrics 2013 Apr 13;98(1):137-155. [doi: 10.1007/s11192-013-1014-8]

51. Chuang KY, Wang MH, Ho YS. High-impact papers presented in the subject category of water resources in the essential science indicators database of the institute for scientific information. Scientometrics 2011 Mar 5;87(3):551-562. [doi: 10.1007/s11192-011-0365-2]

52. Bornmann L, Mutz R, Neuhaus C, Daniel HD. Citation counts for research evaluation: standards of good practice for analyzing bibliometric data and presenting and interpreting results. Ethics Sci Environ Polit 2008 Jun 03;8:93-102. [doi: 10.3354/esep00084]

53. Clarivate A. Clarivate.libguides. 2017. Essential Science Indicators: Learn the Basics URL: http://clarivate.libguides.com/ esi [accessed 2017-08-04] [WebCite Cache ID 6sSIeyJm1]

54. Hirsch JE. An index to quantify an individual's scientific research output. Proc Natl Acad Sci USA 2015 Nov;102(46):16569-16572. [Medline: 16275915]

55. Egghe L. Theory and practise of the g-index. Scientometrics 2013 Jun 20;69(1):131-152. [doi: 10.1007/s11192-006-0144-7]

56. World Bank. Country and Lending Groups URL: https://datahelpdesk.worldbank.org/knowledgebase/articles/ 906519-world-bank-country-and-lending-groups [WebCite Cache ID 6r4c6w6BP]

57. Aria M, Cuccurullo C. Bibliometrix. 2016. Bibliometrix: R package for bibliometric and co-citation analysis URL: http:/ /www.bibliometrix.org [accessed 2017-07-28] [WebCite Cache ID 6sHyJezk4]

58. R-project. Vienna, Austria; 2017. R: A language and environment for statistical computing URL: https://www.r-project.org/ [accessed 2017-07-28] [WebCite Cache ID 6sHygUtqx]

59. Webb TL, Joseph J, Yardley L, Michie S. Using the internet to promote health behavior change: a systematic review and meta-analysis of the impact of theoretical basis, use of behavior change techniques, and mode of delivery on efficacy. J Med Internet Res 2010;12(1):e4 [FREE Full text] [doi: 10.2196/jmir.1376] [Medline: 20164043]

60. Bornmann L, Mutz R. Growth rates of modern science: a bibliometric analysis based on the number of publications and cited references. J Assn Inf Sci Tec 2015 Apr 29;66(11):2215-2222. [doi: 10.1002/asi.23329]

61. Farooq M, McCrory MA, Sazonov E. Reduction of energy intake using just-in-time feedback from a wearable sensor system. Obesity (Silver Spring) 2017 Apr;25(4):676-681. [doi: 10.1002/oby.21788] [Medline: 28233942]

62. Hekler EB, Michie S, Pavel M, Rivera DE, Collins LM, Jimison HB, et al. Advancing models and theories for digital behavior change interventions. Am J Prev Med 2016 Nov;51(5):825-832. [doi: 10.1016/j.amepre.2016.06.013] [Medline: 27745682]

63. Lewis BA, Napolitano MA, Buman MP, Williams DM, Nigg CR. Future directions in physical activity intervention research: expanding our focus to sedentary behaviors, technology, and dissemination. J Behav Med 2017 Feb;40(1):112-126. [doi: 10.1007/s10865-016-9797-8] [Medline: 27722907]

64. Müller AM, Blandford A, Yardley L. The conceptualization of a Just-In-Time Adaptive Intervention (JITAI) for the reduction of sedentary behavior in older adults. Mhealth 2017 Sep;3:37 [FREE Full text] [doi: 10.21037/mhealth.2017.08.05] [Medline: 29184889]

65. Ottaviani J. The post-embargo open access citation advantage: it exists (probably), its modest (usually), and the rich get richer (of course). PLoS One 2016;11(8):e0159614 [FREE Full text] [doi: 10.1371/journal.pone.0159614] [Medline: 27548723]

66. Eysenbach G. Citation advantage of open access articles. PLoS Biol 2006 May;4(5):e157 [FREE Full text] [doi: 10.1371/journal.pbio.0040157] [Medline: 16683865]

67. Wray KB. No new evidence for a citation benefit for Author-Pay Open Access Publications in the social sciences and humanities. Scientometrics 2016 Jan 12;106(3):1031-1035. [doi: 10.1007/s11192-016-1833-5]

68. Sotudeh H, Ghasempour Z, Yaghtin M. The citation advantage of author-pays model: the case of Springer and Elsevier OA journals. Scientometrics 2015 Jun 3;104(2):581-608. [doi: 10.1007/s11192-015-1607-5] 
69. Goryakin Y, Lobstein T, James WP, Suhrcke M. The impact of economic, political and social globalization on overweight and obesity in the 56 low and middle income countries. Soc Sci Med 2015 May;133:67-76 [FREE Full text] [doi: 10.1016/j.socscimed.2015.03.030] [Medline: 25841097]

70. Popkin BM. Global nutrition dynamics: the world is shifting rapidly toward a diet linked with noncommunicable diseases. Am J Clin Nutr 2006 Aug;84(2):289-298 [FREE Full text] [Medline: 16895874]

71. Hyder AA, Wosu AC, Gibson DG, Labrique AB, Ali J, Pariyo GW. Noncommunicable disease risk factors and mobile phones: a proposed research agenda. J Med Internet Res 2017 May 05;19(5):e133 [FREE Full text] [doi: 10.2196/jmir.7246] [Medline: 28476722]

72. Reis RS, Salvo D, Ogilvie D, Lambert EV, Goenka S, Brownson RC, Lancet Physical Activity Series 2 Executive Committee. Scaling up physical activity interventions worldwide: stepping up to larger and smarter approaches to get people moving. Lancet 2016 Sep 24;388(10051):1337-1348. [doi: 10.1016/S0140-6736(16)30728-0] [Medline: 27475273]

73. Zhao J, Freeman B, Li M. Can mobile phone apps influence people's health behavior change? An evidence review. J Med Internet Res 2016 Oct 31;18(11):e287 [FREE Full text] [doi: 10.2196/jmir.5692] [Medline: 27806926]

74. Fjeldsoe B, Neuhaus M, Winkler E, Eakin E. Systematic review of maintenance of behavior change following physical activity and dietary interventions. Health Psychol 2011 Jan;30(1):99-109. [doi: 10.1037/a0021974] [Medline: 21299298]

75. Michie S, Abraham C, Whittington C, McAteer J, Gupta S. Effective techniques in healthy eating and physical activity interventions: a meta-regression. Health Psychol 2009 Nov;28(6):690-701. [doi: 10.1037/a0016136] [Medline: 19916637]

76. Tremblay MS, Aubert S, Barnes JD, Saunders TJ, Carson V, Latimer-Cheung AE, SBRN Terminology Consensus Project Participants. Sedentary Behavior Research Network (SBRN) - Terminology Consensus Project process and outcome. Int J Behav Nutr Phys Act 2017 Jun 10;14(1):75 [FREE Full text] [doi: 10.1186/s12966-017-0525-8] [Medline: 28599680]

77. Uthman OA, Okwundu CI, Wiysonge CS, Young T, Clarke A. Citation classics in systematic reviews and meta-analyses: who wrote the top 100 most cited articles? PLoS One 2013;8(10):e78517. [doi: 10.1371/journal.pone.0078517] [Medline: 24155987]

78. Evans D. Hierarchy of evidence: a framework for ranking evidence evaluating healthcare interventions. J Clin Nurs 2003 Jan;12(1):77-84. [Medline: 12519253]

79. Blank I, Rokach L, Shani G. Leveraging metadata to recommend keywords for academic papers. J Assn Inf Sci Tec 2016 Mar 15;67(12):3073-3091. [doi: 10.1002/asi.23571]

80. Bornmann L. What is societal impact of research and how can it be assessed? A literature survey. J Am Soc Inf Sci Tec 2012 Dec 17;64(2):217-233. [doi: 10.1002/asi.22803]

81. Bornmann L. Do altmetrics point to the broader impact of research? An overview of benefits and disadvantages of altmetrics. J Informetr 2014 Oct;8(4):895-903. [doi: 10.1016/j.joi.2014.09.005]

82. Piwowar H. Altmetrics: Value all research products. Nature 2013 Jan 10;493(7431):159. [doi: 10.1038/493159a] [Medline: 23302843]

\section{Abbreviations}

eHealth: electronic health

eHealth: electronic health

NCD: Noncommunicable disease

SMS: short message service

WoS: Web of Science

Edited by G Eysenbach; submitted 26.09.17; peer-reviewed by M Bardus, R Hand; comments to author 08.11.17; revised version
received 17.12.17; accepted 17.12.17; published 18.04.18
Please cite as:
Müller AM, Maher CA, Vandelanotte C, Hingle M, Middelweerd A, Lopez ML, DeSmet A, Short CE, Nathan N, Hutchesson MJ, Poppe
L, Woods CB, Williams SL, Wark PA
Physical Activity, Sedentary Behavior, and Diet-Related eHealth and mHealth Research: Bibliometric Analysis
J Med Internet Res 2018;20(4):e122
URL: $\underline{\text { http://www.jmir.org/2018/4/e122/ }}$
doi: $10.2196 / j m i r .8954$
PMID: $\underline{29669703}$

(C)Andre Matthias Müller, Carol A Maher, Corneel Vandelanotte, Melanie Hingle, Anouk Middelweerd, Michael L Lopez, Ann DeSmet, Camille E Short, Nicole Nathan, Melinda J Hutchesson, Louise Poppe, Catherine B Woods, Susan L Williams, Petra A Wark. Originally published in the Journal of Medical Internet Research (http://www.jmir.org), 18.04.2018. This is an open-access 
article distributed under the terms of the Creative Commons Attribution License (https://creativecommons.org/licenses/by/4.0/), which permits unrestricted use, distribution, and reproduction in any medium, provided the original work, first published in the Journal of Medical Internet Research, is properly cited. The complete bibliographic information, a link to the original publication on http://www.jmir.org/, as well as this copyright and license information must be included. 